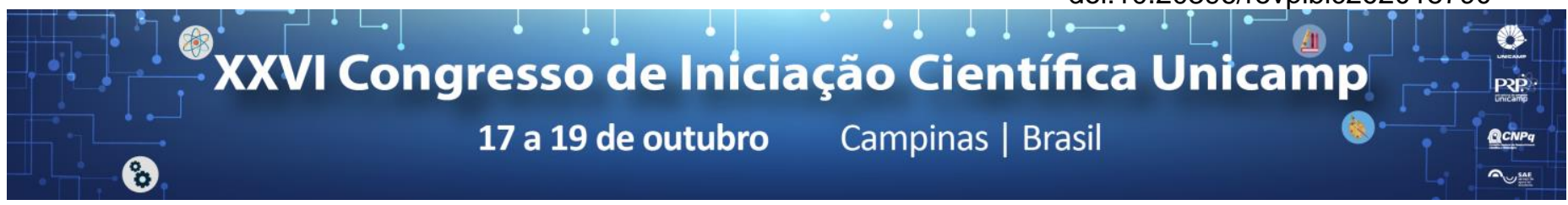

\title{
Análise de protestos e greves no Brasil (1999-2016)
}

\section{Larissa Vicentin Gramacho, Andreia Galvao}

\section{Resumo}

Este trabalho é a continuação e aprofundamento do projeto "Levantamento e montagem de banco de dados sobre protestos e greves no Brasil (1999-2016)", realizado no ano anterior e que se insere num projeto de pesquisa coletivo que tem como objetivo de construir um banco de dados sobre protestos e greves no Brasil realizados entre 1999 e 2016, a partir da análise de registros em jornais de circulação nacional, sendo esta pesquisa individual com ênfase nos protestos das bases sociais de cunho identitário - negros, mulheres, imigrantes, LGBT, deficientes, religiosos e familiares.

\section{Palavras-chave:}

Protestos, greves, banco de dados.

\section{Introdução}

O objetivo principal desse trabalho de pesquisa é mapear os eventos de protesto ocorridos em todo território nacional, no período de 1999 a 2016, relacionando-os com a bibliografia e observando a trajetória desses acontecimentos e suas possíveis variações de acordo com os governos FHC, Lula e Dilma. A base teórica para análise dos dados obtidos são a teoria do confronto político (McADAM, D.; TARROW, S; TILLY, C, 2001), articulada à abordagem marxista sobre os movimentos sociais (BARKER, 2013).

Para tanto, realizou-se a leitura sistemática dos principais cadernos do jornal Folha de São Paulo, inserindo os eventos em um banco de dados subdividido em diversas categorias, como data, base social mobilizada, local, objetivo, número de participantes, entre outras.

\section{Resultados e Discussão}

A discussão teórica que será a base para a análise e discussão dos dados é a teoria do confronto político (McADAM, D.; TARROW, S; TILLY, C, 2001), articulada à abordagem marxista sobre os movimentos sociais (BARKER et al, 2013). Além destas referências, olhar para os movimentos de identidade especificamente também requer a abordagem da teoria dos novos movimentos sociais (MELUCCl, 1989). A teoria dos novos movimentos sociais é importante para entender os movimentos de mulheres, negros, LGBT e outros porque não considera apenas a estrutura ou a mobilização de recursos para explicar a ação coletiva, mas considera principalmente o caráter cultural e a busca por afirmação de uma identidade dentro da sociedade, através da mudança de mentalidade e valores, podendo abrir mão das relações com o Estado para isso.

O que se observa na base de dados que já foi parcialmente consolidada é uma relação articulada entre os grupos identitários e os grupos sindicais. Nos dados de 2011 a 2016, que já estão consolidados, foram identificados 86 protestos, dentre 1813, que mobilizaram mais de uma base social, sendo a maior parte dos protestos conjuntos entre estudantes e trabalhadores -23 ao todo. Os motivos que agregam essas duas bases sociais são diversos, e vão desde questões específicas de escolas e universidades, como reajuste salarial e melhores condições de trabalho, até questões mais gerais como cotas raciais e contra a reorganização escolar, projeto apresentado por Geraldo Alckmin, governador de São Paulo, em 2015.

\section{Conclusões}

A coleta de dados dos protestos no jornal Folha de São Paulo dos anos 2003 a 2016 já foi concluída, gerando o total de mais de 5000 entradas no software, sendo que algumas destas correspondem ao mesmo evento. Os anos de 1999 a 2002 ainda estão em fase de revisão e consolidação, e análise do banco de dados completo será realizada em breve.

\section{Agradecimentos}

Ao Programa Institucional de Bolsas de Iniciação Científica - PIBIC e ao Conselho Nacional de Desenvolvimento Científico e Tecnológico - CNPq.

McADAM, D.; TARROW, S; TILLY, C. Dynamics of Contention. Cambridge and New York: Cambridge University Press, 2001.

BARKER, C. et al. Marxism and Social Movements: An Introduction in Barker Colin, Cox Laurence, Krinsky John, Gunvald Nilsen Alf, ed, Marxism and Social Movements, Leiden/Boston, Brill, 2013, p. 1-37.

MELUCCI, Alberto. Um objetivo para os movimentos sociais?. Lua Nova: revista de Cultura e política, n. 17, p. 49-66, 1989. 